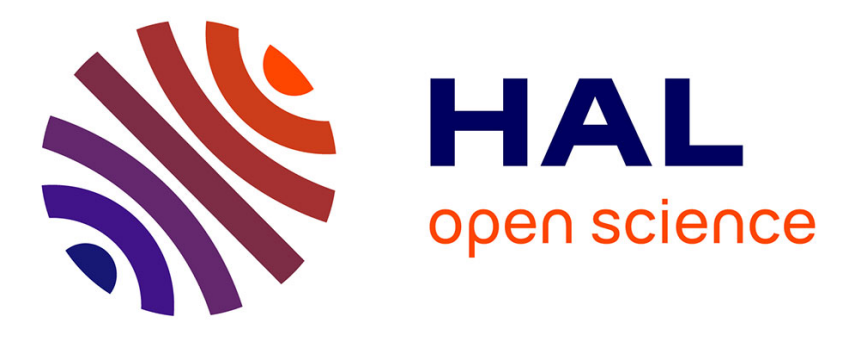

\title{
Mechanical behavior of nickel base foams for diesel particle filter applications
}

M. Duchamp, Jean-Dominique Bartout, Samuel Forest, Yves Bienvenu, G. Walther, S. Saberi, A. Boehm

\section{- To cite this version:}

M. Duchamp, Jean-Dominique Bartout, Samuel Forest, Yves Bienvenu, G. Walther, et al.. Mechanical behavior of nickel base foams for diesel particle filter applications. Mechanical properties of cellular materials, Sep 2007, Cachan, France. pp.51-67, 10.1007/978-1-4020-9404-0 . hal-00379128

\section{HAL Id: hal-00379128 \\ https://hal.science/hal-00379128}

Submitted on 29 Jun 2009

HAL is a multi-disciplinary open access archive for the deposit and dissemination of scientific research documents, whether they are published or not. The documents may come from teaching and research institutions in France or abroad, or from public or private research centers.
L'archive ouverte pluridisciplinaire HAL, est destinée au dépôt et à la diffusion de documents scientifiques de niveau recherche, publiés ou non, émanant des établissements d'enseignement et de recherche français ou étrangers, des laboratoires publics ou privés. 


\title{
Mechanical behavior of Nickel base foams for Diesel Particle Filter applications
}

\author{
M. Duchamp ${ }^{1}$, J.D. Bartout ${ }^{1}$, S. Forest ${ }^{1}$, Y. Bienvenu ${ }^{1}$, G. Walther ${ }^{2}$, \\ S. Saberi ${ }^{3}$, and A. Boehm ${ }^{4}$ \\ 1 Centre des Matériaux, Mines Paris, Paristech, CNRS UMR 7633, BP 87, 91003 \\ Evry Cedex, France, samuel.forest@ensmp.fr \\ 2 Fraunhofer-Institut, IFAM, Dresden, Germany \\ 3 Inco SP, Mississauga, Canada \\ 4 Inco GmbH, Munich, Germany
}

Summary. An original processing route by powder metallurgy was developped to alloy pure Ni foams so, that the foam becomes refractory for high temperature applications. The modelling of such a foam at high temperature starts from the behavior of the basic constitutive material, then we use micromechanical models to predict the mechanical properties under tension and in compression creep. A 3D finite element analysis of a volume analysed by X-ray tomography is performed to study the foam deformation mechanisms in both conditions.

\section{Introduction}

Open-cell Ni foams are mainly used as battery electrodes. The very large specific surface of the INCOFOAM ${ }^{\circledR}$ pure $\mathrm{Ni}$ foams also leads to outstanding filtration properties $[1,2]$. A Diesel Particulate Filter (DPF) application requires the alloying of the INCOFOAM ${ }^{\circledR}$ material to improve the oxidation resistance and to provide thermal stability. For that purpose, a foam alloying route using powder metallurgy was developed by INCO and IFAM (patent number: DE 10301 175.7). The alloyed foams designed for the DPF application are named INCOFOAM ${ }^{\circledR}$ HighTemp . The typical alloy composition of the foams studied in this work is that of Inconel 625. A short review of the alloying techniques is given in $[17,18]$. Inconel 625 foams were recently synthesized by powder metallurgy in $[13,14]$ and by vapor deposition in [12].

The objective of the work is to provide tools for the design of DPF considering critical aspects of the life-time of a real filter, from its manufacturing to the in service conditions. The manufacturing of complex filter shapes can induce damage in the foam that could affect the durability of the filter component. Creep in the filter is likely to start during high temperature regeneration regime. 
A predictive model for tensile properties for both $\mathrm{Ni}$ and alloyed foams is presented. It assumes that the bending of the struts is the main deformation mechanism in the foam [10]. A simplified morphology is deduced from 3D reconstruction of microtomography of $\mathrm{Ni}$ foams [3], 2D image analysis and electrical resistivity measurements. Creep of alloyed foams is also investigated in this work. Two creep mechanisms are evidenced from the experimental point of view and we confronted an existing model [18] to a large experimental data set of alloyed foams creep measurements. The proposed model describes better high temperature (above $800^{\circ} \mathrm{C}$ ) creep than low temperature creep. A 3D investigation of microtomographic foam images with the Finite Elements Method is finally used in order to assess the assumptions of the models presented before.

\section{Materials and experimental techniques}

\subsection{Materials}

The Ni base alloyed foams are obtained by a powder metallurgy alloying route using pure Ni foams INCOFOAM ${ }^{\circledR}$ as a template. The materials considered in this work are given in table 1 . The INCOFOAM ${ }^{\circledR}$ are produced as foam plates and we distinguish a coiling direction $\mathrm{RD}$, a transverse direction $\mathrm{TD}$ and the normal direction ND. The process is divided into three steps: binding, coating and finally sintering. The amount and the composition of the powder sintered on the foam is set to reach the theoretical composition of Inconel 625 . SEM pictures of both a pure Ni foam INCOFOAM ${ }^{\circledR}$ and an alloyed foam INCOFOAM ${ }^{\circledR}$ HighTemp having the same initial morphology are presented in figure 1. The porous Ni foam structure is not affected by alloying. In both cases, the hollow struts can be seen. We define the volume fraction $\Phi$ of a foam as the ratio between the solid volume and the total volume of the foam. We also define the mechanical volume fraction of a foam $\Phi_{\text {mech }}$ which is the volume fraction of the foam that really contributes to the mechanical properties of the foam. For pure Ni foams, we consider that $\Phi_{m e c h}=\Phi_{N i}$ whereas for alloyed foams, we can see on figure 1 that a reduced part of the sintered particles mass really contributes to the mechanical properties of the foam. For the alloyed foams, we deduce $\Phi_{N i} \leq \Phi_{m e c h} \leq \Phi_{\text {Alloyed }}$. This point will be discussed further in this work.

We also applied the alloying procedure by powder metallurgy to $10 \mu \mathrm{m}$ thick pure $\mathrm{Ni}$ foils to study the influence of the alloying process on the constitutive material of the foam. A cross section SEM picture of the alloyed foil is given in figure 2 .

Microtomography analyses $[3,4]$ on $\mathrm{Ni}$ foams have shown that the cell volume distribution is monomodal and centered on $0.025 \mathrm{~mm}^{3}$. The corresponding cell diameter is equal to $390 \mu \mathrm{m}$. The cells are not spherical but elongated 
ellipsoids. Their main axes called $a<b<c$ have also a monomodal distribution centered on $a=316 \mu \mathrm{m}, b=399 \mu \mathrm{m}$ and $c=479 \mu \mathrm{m}$. The ratios of the equivalent axes $R=b / a$ and $Q=c / a$ represent the morphological anisotropy of the foam. We have: $R=1.27$ and $Q=1.52$. These axes have a preferential orientation in the space linked to the manufacturing process: $a$-axes are mainly oriented in the TD direction, $b$ and $c$-axes are tilted in the ND-RD plane (see figure 6). The strut length distribution is monomodal centered on $149 \mu \mathrm{m}$.

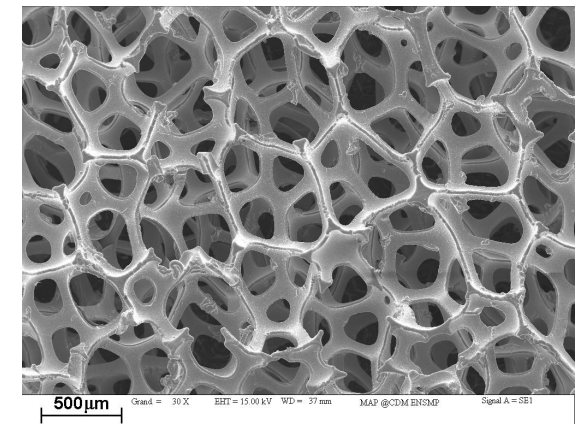

(a)

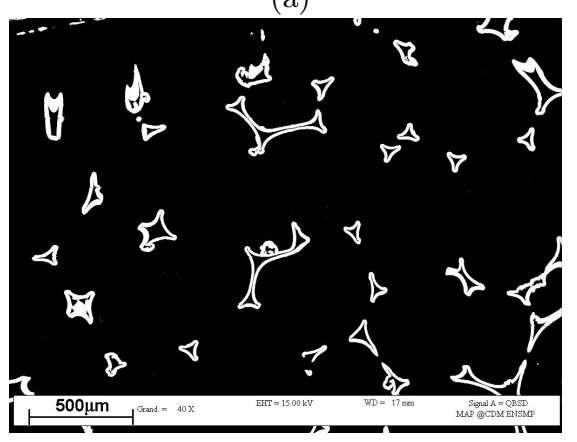

(c)

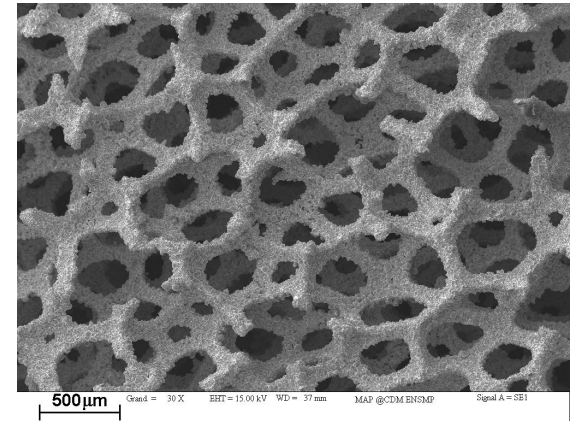

(b)

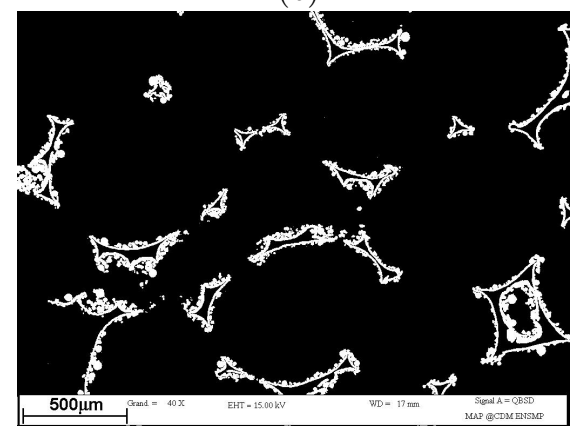

(d)

Fig. 1. SEM pictures of (a) initial Ni foam (b) alloyed foam (c) initial Ni foam cross section (d) alloyed foam cross section.

\subsection{Experimental techniques}

Tensile tests were carried out on all foam types presented in table 1. Dogbone tensile samples were cut out of the foam strips. They were tested in a conventional tensile testing machine at room temperature. Load was measured with a $500 \mathrm{~N}$ load cell and elongation was measured with a light resistive extensometer (gauge length $100 \mathrm{~mm}$ ). Tensile tests were carried out on the foils presented in table 1 . 


\begin{tabular}{|c|c|c|c|c|c|}
\hline \multicolumn{7}{|c|}{ Ni Foams INCOFOAM } \\
\hline $\begin{array}{c}\text { Label } \\
\Phi(\%)\end{array}$ & $\begin{array}{c}\text { Electrical } \\
\text { anisotropy }\end{array}$ & $\begin{array}{c}\text { Measured cell } \\
\text { diameter } a(\mu \mathrm{m})\end{array}$ & $\begin{array}{c}\text { Cell size } \\
(\mu \mathrm{m})\end{array}$ & $\begin{array}{c}\text { Thickness } \\
(\mathrm{mm})\end{array}$ & $\begin{array}{c}\text { Manufact. } \\
\text { process }\end{array}$ \\
\hline C450 3.2 & 1.66 & 288 & 450 & 1.5 & CVD \\
C450 2.6 & 1.27 & $\mathrm{~N} / \mathrm{C}$ & 450 & 1.6 & CVD \\
C450 13 & 1.64 & $316^{*}$ & 450 & 1.5 & CVD \\
\hline D580 2.5 & 1.36 & 382 & 580 & 1.9 & EP \\
D580 2.1 & 1.44 & $\mathrm{~N} / \mathrm{C}$ & 580 & 1.9 & EP \\
\hline D800 2.1 & 1.39 & 466 & 800 & 2.5 & EP \\
D800 1.6 & 1.46 & N/C & 800 & 2.5 & EP \\
\hline D1200 1.9 & 1.36 & 788 & 1200 & 3.0 & EP \\
D1200 1.3 & 1.18 & N/C & 1200 & 3.0 & EP \\
\hline
\end{tabular}

\begin{tabular}{|c|c|c|c|c|}
\hline \multicolumn{5}{|c|}{ Alloyed Foams INCOFOAM ${ }^{\circledR}$ HighTemp } \\
\hline $\begin{array}{l}\text { Label } \\
\Phi(\%)\end{array}$ & $\begin{array}{l}\text { Electrical } \\
\text { anisotropy }\end{array}$ & $\begin{array}{c}a \\
(\mu \mathrm{m})\end{array}$ & $\begin{array}{c}\text { Thickness } \\
\text { (mm) }\end{array}$ & $\begin{array}{l}\text { Ni base } \\
\text { foam }\end{array}$ \\
\hline A763 8.4 & 1.65 & 285 & 1.5 & C450 3.2 \\
\hline A808 7.6 & 1.08 & 295 & 1.6 & C450 2.6 \\
\hline $\mathrm{A} 7$ & & $42-2>$ & 2.0 & $\bar{D} 5802.5$ \\
\hline A809 5.5 & 1.25 & 353 & 2.0 & D580 2.1 \\
\hline 9 & & 650 & 2.5 & D800 2.1 \\
\hline A810 3.8 & 1.54 & 522 & 2.5 & D800 1.6 \\
\hline A793 4.7 & 1.2 & 80 & 3.1 & D1200 1.9 \\
\hline A811 2.8 & 1.34 & 724 & 3.1 & D1200 1.3 \\
\hline
\end{tabular}

\begin{tabular}{|c|c|c|}
\hline \multicolumn{3}{|c|}{ Foils } \\
\hline Label & $\begin{array}{c}\text { Constitutive } \\
\text { material }\end{array}$ & $\begin{array}{c}\text { Foil } \\
\text { thickness }(\mu \mathrm{m})\end{array}$ \\
\hline FCommercial & Commercial Inconel 625 & 25 \\
FAlloyed & IN625 & 10 \\
\hline
\end{tabular}

Table 1. Materials used for this study. CVD is used for Chemical Vapor Deposition and EP for ElectroPlating.

Monotonic compression and creep compression tests were also carried out on the alloyed foams. Discs (diameter $20 \mathrm{~mm}$ ) were cut out of the foam strip with a turning lathe and tested at high temperature in a radiative furnace. The applied creep stress levels are set close to the plateau stress of the compressive stress-strain curves of the foams.

Resistivity measurements were performed on foam samples $(20 \mathrm{~cm} \times 3$ $\mathrm{cm})$ cut in RD and TD with a modified four wire technique. The electrical anisotropy is the ratio of resistivity in the TD and the RD directions. It was applied on both $\mathrm{Ni}$ foams and alloyed foams. This measure gives a good 


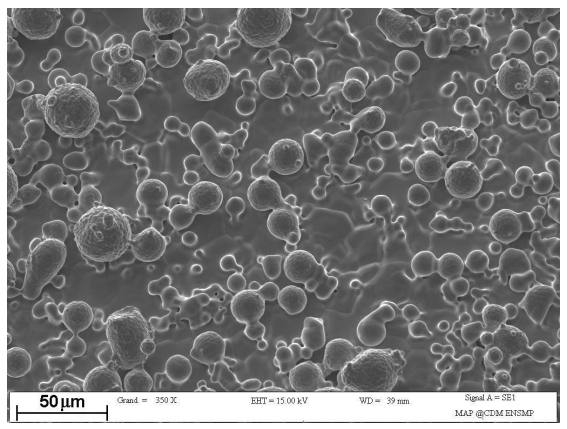

(a)

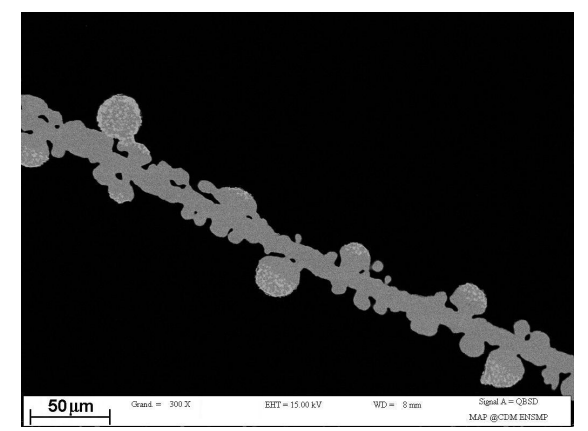

(b)

Fig. 2. Alloyed Ni foil with powder metallurgy. SEM picture of (a) the foil surface (b) the foil cross section.

approximation of foam anisotropy [7]. The ratio of measured resistivity along directions TD, $\Omega_{T D}$ and $\mathrm{RD}, \Omega_{R D}$ give the anisotropy ratio assuming the model of figure 6 . This ratio is called electrical anisotropy in table 1.

$$
\frac{\Omega_{T D}}{\Omega_{R D}}=\frac{c}{a}=Q
$$

The measured electrical anisotropy values lye between 1.18 and 1.66.

\section{Experimental results}

\subsection{Tensile tests}

Tensile tests were performed at room temperature on pure Ni foams and alloyed foams. Some tensile curves are given in figure 3 and 4 . As already observed in [7], foams have a strongly anisotropic behavior. The stress levels along RD are about twice the stress level along TD. Another effect is the stiffening of the foam due to the alloying process. The stress level is about five times higher for the alloyed foam. We observe a certain embrittlement due to the alloying process. The ductility of the foams is divided by a factor two.

Tensile tests were also performed on the foils presented in table 1. The commercial foil FCommercial exhibits a stress peak typical for superalloy tensile curves whereas the alloyed foil FAlloyed exhibits a smoother behavior. This can be due to the wrinkling of the foil surface caused by capillarity forces during the high temperature sintering process. The foil FAlloyed, obtained by powder metallurgy technique, is less ductile. The ultimate strain at fracture is five times lower than that of the commercial foil FCommercial. We identified an elastoplastic constitutive model with the von Mises criterion $f$ and a linear hardening coefficient $H$ described by the equations 2 to 3 . The calibrated 

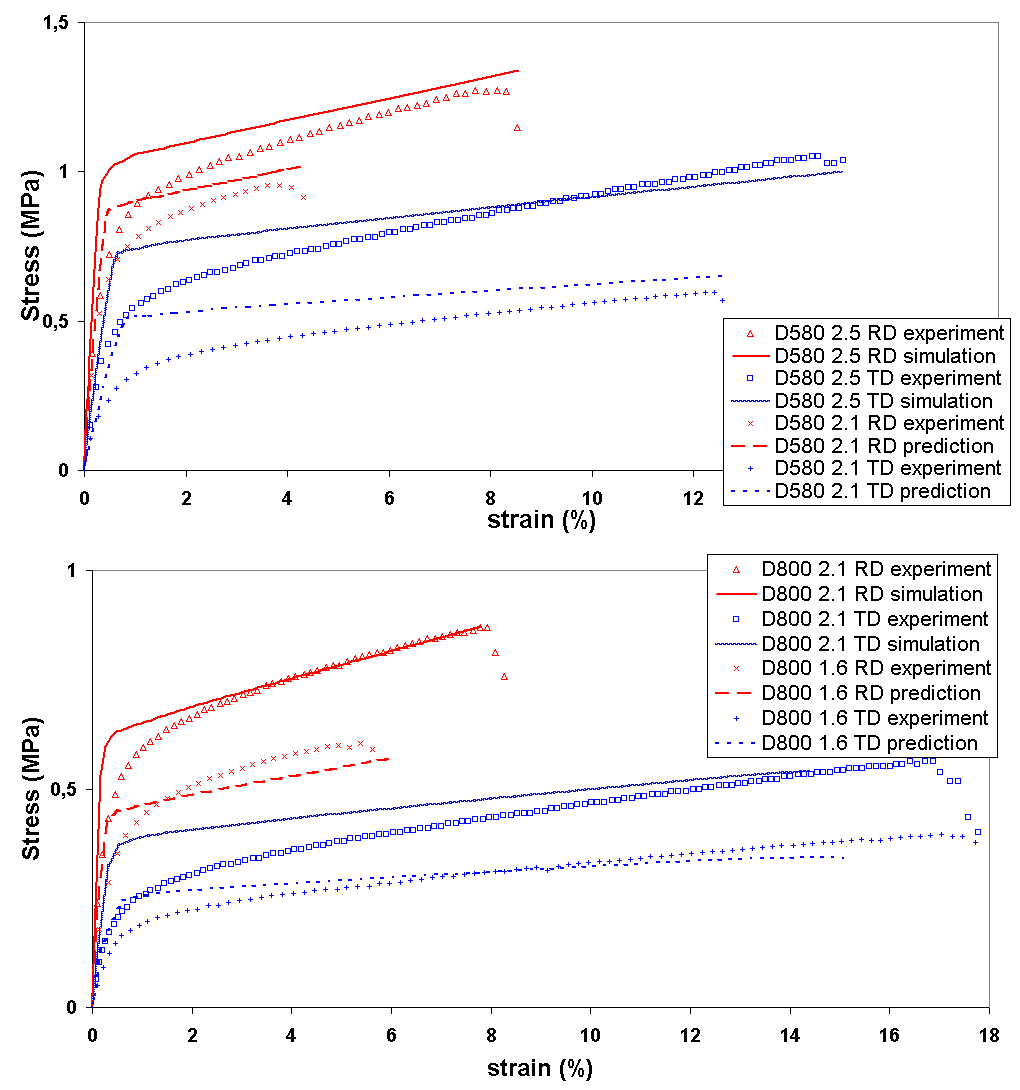

Fig. 3. Experimental, simulated and predicted tensile tests of foam strips cut in the RD and the TD of (top) D580 2.5 and D580 2.1 (bottom) D800 2.1 and D800 1.6.

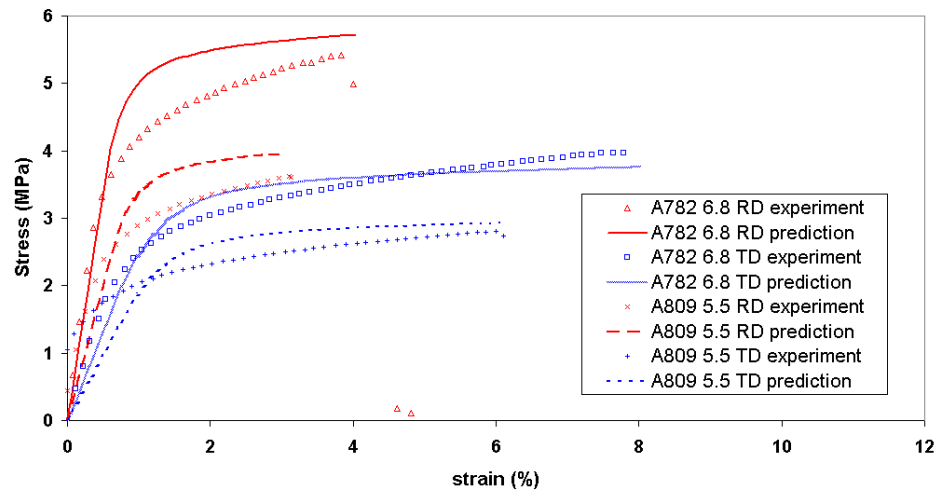

Fig. 4. Experimental and predicted tensile tests of foam strips cut in the RD and the TD of A782 6.8 and A809 5.5. 
parameters can be found in 2 as well as the parameters for $10 \mu \mathrm{m}$ thick pure $\mathrm{Ni}$ foils found in [6].

$$
\begin{gathered}
\varepsilon=\varepsilon^{e}+\varepsilon^{p}, \quad f(\sigma)=\sqrt{\frac{3}{2} \sigma^{d e v}: \sigma^{d e v}}-\sigma_{y} \\
\sigma_{y}=\sigma_{0}+H p, \quad \dot{\varepsilon}^{p}=\dot{p} \frac{\partial f}{\partial \sigma}
\end{gathered}
$$

where $\sigma^{d e v}$ is the deviatoric part of the stress tensor and $p$ the equivalent plastic deformation.

\begin{tabular}{|c|c|c|c|}
\hline & $\begin{array}{c}\text { Young's modulus } \\
\mathrm{E}(\mathrm{GPa})\end{array}$ & $\begin{array}{c}\text { Yield stress } \\
\sigma_{0}(\mathrm{MPa})\end{array}$ & $\begin{array}{c}\text { Hardening modulus } \\
\mathrm{H}(\mathrm{MPa})\end{array}$ \\
\hline FCommercial & 200 & 478 & 5800 \\
FAlloyed & 200 & 373 & 2080 \\
Pure Ni foil [6] & 204 & 70 & 1800 \\
\hline
\end{tabular}

Table 2. Identified material data of the linear hardening law (equations 2 to 3 ) for foils FCommercial, FAlloyed and a $10 \mu \mathrm{m}$ pure Ni foil [6].

\subsection{Creep tests}

Creep tests were performed on alloyed foam disks. When a constant stress is applied, a steady-state strain rate occurs after a short transient. The steadystate strain rate of cellular materials can be related to the uniaxial stress by the power law:

$$
\dot{\varepsilon}^{*}=A^{*} \sigma^{* n^{*}}
$$

where the constant $A^{*}$ depends on the temperature. This equation is the analogous to the power law equation for bulk materials (with the macroscopic constants $A^{*}$ and $n^{*}$ ) like in equation 9 . We tested the alloyed foams at $500^{\circ} \mathrm{C}$, $600^{\circ} \mathrm{C}, 700^{\circ} \mathrm{C}$, and $800^{\circ} \mathrm{C}$ and we plotted the stress and the strain rate values in figure 5. A transition in the $n^{*}$ creep stress exponent is observed for stress values in the order of $0.5 \mathrm{MPa}$ at temperatures above $700^{\circ} \mathrm{C}$ and stress values in the order of $1 \mathrm{MPa}$ at temperature below $700^{\circ} \mathrm{C}$. We identified the constants $A^{*}$ and $n^{*}$ (see table 3 ) for low stresses and high stresses. The low stress regime $n$ mean value is equal to 1.0 , high stress regime $n$ mean value is equal to 4.2 . 


\begin{tabular}{|c|c|c|c|c|c|}
\hline & & \multicolumn{2}{|c|}{ Low stress } & \multicolumn{2}{|r|}{ High stress } \\
\hline $\begin{array}{l}\text { Alloyed } \\
\text { foams }\end{array}$ & $\begin{array}{c}\text { Temperature } \\
{ }^{\circ} \mathrm{C}\end{array}$ & $\begin{array}{l}n^{*} \\
(-)\end{array}$ & $\begin{array}{c}A^{*} \\
\left(\mathrm{MPa}^{-n^{*}} \mathrm{~s}^{-1}\right)\end{array}$ & \begin{tabular}{l|}
$n^{*}$ \\
$(-)$
\end{tabular} & $\begin{array}{c}A^{*} \\
\left(\mathrm{MPa}^{-n^{*}} \mathrm{~s}^{-1}\right)\end{array}$ \\
\hline A793 4.7 & 600 & $7.610^{-2}$ & $1.410^{-7}$ & 5.7 & $2.310^{-8}$ \\
\hline & 700 & 1.7 & $1.910^{-5}$ & 3.4 & $1.610^{-5}$ \\
\hline A790 4.9 & 500 & 1.5 & $1.110^{-8}$ & 6.6 & $7.610^{-10}$ \\
\hline & 800 & 1.7 & $9.810^{-6}$ & 6.4 & $3.710^{-5}$ \\
\hline A782 6.8 & 600 & 1.2 & $1.110^{-7}$ & 2.8 & $5.310^{-8}$ \\
\hline & 700 & 1.1 & $7.210^{-6}$ & 2.5 & $4.510^{-6}$ \\
\hline A808 7.6 & 700 & $3.110^{-1}$ & $8.310^{-7}$ & 2.3 & $4.410^{-7}$ \\
\hline A809 5.5 & 700 & $7.810^{-1}$ & $1.110^{-6}$ & 3.3 & $1.310^{-6}$ \\
\hline A810 3.8 & 700 & $4.610^{-1}$ & $1.710^{-6}$ & 3.6 & $4.210^{-6}$ \\
\hline A811 2.8 & 700 & 1.0 & $1.710^{-6}$ & 5.1 & $5.010^{-6}$ \\
\hline
\end{tabular}

Table 3. Power-law equation parameters for different kinds of INCOFOAM ${ }^{\circledR}$ HighTemp .

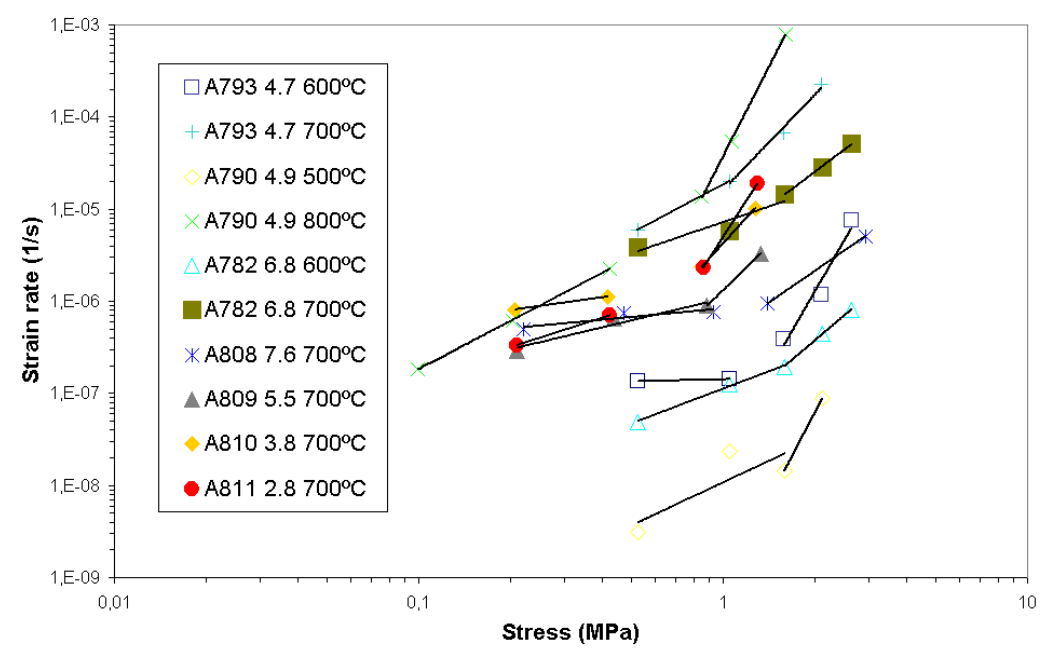

Fig. 5. Log-log diagram for different INCOFOAM ${ }^{\circledR}$ HighTemp types tested at different temperatures. 


\section{Modeling of the foam behavior}

\subsection{Tensile elastoplastic behavior of foams}

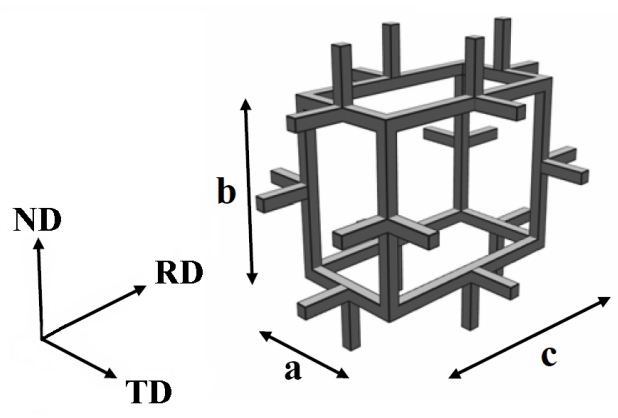

Fig. 6. Simplified foam cell elongated in the coiling direction.

A simple mechanical model for pure $\mathrm{Ni}$ and of alloyed foams in tension at room temperature is presented. It incorporates the previous morphological parameters (parameters $\Phi, Q, R$ and the measured cell equivalent axis $a$ ).

The model is based on the assumption that the bending of the struts is the main deformation mechanism of the foam [10]. The idealized cell geometry of figure 6 is used to link the morphological parameters to the foam volume fraction $\Phi$ :

$$
\Phi=\frac{4 t^{2}(a+b+c)}{a b c}=\frac{4 t^{2}}{a^{2}} \frac{Q+R+1}{R Q}
$$

where $t$ the beams thickness. Subsequently, the anisotropy ratio $\mathrm{R}$ is taken equal to 1 for simplicity.

When the cell is deformed in the direction parallel to the RD, the beams parallel to TD and ND are bent. The bending of the nonlinear beams is computed with the Finite Element Method using 2D simulation under plane stress conditions. Prescribing the bending of a strut in the plane by applying an angle $\theta$ to the right edge, we compute the deflection $\delta$ of the beam and we post-process the bending moment $M$ in the beam at each step of the computation. When the foam is tested in the RD direction, then the beams of length $a$ and $b$ and of thickness $t$ are bent. We impose that $\delta_{a}=\delta_{b}=\delta_{R D}$ and we compute both the bending moments in the $a$ beam $M_{a}$ and in the $b$ beam $M_{b}$. When the foam is tested in the TD direction, we apply the same procedure to $b$ and $c$ beams.

Then, scale transition rules are introduced to link the deflection to the overall deformation of the foam, on the one hand, and between the bending moment moment on a single beam and the foam stress, on the other hand. 
Scale transition parameters $B$ and $C$ are introduced in equations 6 and 7 . They depend on the foam morphology. They are identified from the macroscopic stress-strain curves for a given morphology of $\mathrm{Ni}$ foams: $B=0.4 \pm 0.1$ and $C=95 \pm 25$. These values are valid for a wide range of $\mathrm{Ni}$ foams morphologies ( $450 \mu \mathrm{m}, 580 \mu \mathrm{m}, 800 \mu \mathrm{m}$ and $1200 \mu \mathrm{m}$ cell size). The influence of the choice of the cross section of the beam can also be shown to affect the parameter $B$ and $C$. For simplicity, a rectangular section is chosen. Subsequently, the constants $B$ and $C$ identified for a pure $\mathrm{Ni}$ foam morphology are kept unchanged to predict the behavior of lighter pure Ni foams and to predict the behavior of the corresponding alloyed foams.

$$
\begin{array}{ll}
\sigma_{R D}^{*}=\frac{C}{a b}\left(\frac{M_{a}}{a^{2}}+\frac{M_{b}}{b^{2}}\right), & \varepsilon_{R D}^{*}=B \frac{\delta_{R D}}{c} \\
\sigma_{T D}^{*}=\frac{C}{b c}\left(\frac{M_{b}}{b^{2}}+\frac{M_{c}}{c^{2}}\right), & \varepsilon_{T D}^{*}=B \frac{\delta_{T D}}{a}
\end{array}
$$

In figure 3 , the calibrated tensile curves are plotted with the experimental tensile curves for two different Ni foam morphologies D580 2.5 (b) D800 2.1 (solid lines), and for the lighter foams inherited from the same foam morphology (a) D580 2.1 (b) D800 1.6 (dash lines). The anisotropy changes slightly, the thickness $t$ of the beams decreased and the parameter $a$ was taken constant equal to $382 \mu \mathrm{m}$. We observe a good agreement between the model and the experiment for the stress levels. However, yield stresses are over-estimated. This is a consequence of the idealized elongated cell orientation along RD. If the cells had a distributed orientation in the RD-TD plane, the elastic-plastic transition domain would be smoother.

The alloying process of foams has two effects on the foams mechanical properties: the foam constitutive material strengthening and the increasing of the mechanical volume fraction. Our assumption is that the first phenomenon is the most important: $\Phi_{m e c h}=\Phi_{N i}$. The behavior law of the FAlloyed (section 3.1) representing the constitutive material is implemented in the model to predict the stress-strain curves of the alloyed foams A782 6.8 (based on the D580 2.5) and A809 5.5 (based on the D580 2.1). Parameter $Q$ is set to the measured value but we kept unchanged the other morphological parameters. In particular, the scale transition parameters $B$ and $C$ are the parameters calibrated on the D580 $2.5 \mathrm{Ni}$ foam. In figure 4, the predicted and the experimental tensile curves are plotted. We observe a good agreement between experimental and predicted curves. The yield stress of foams is overestimated for the predictions in the RD and the elastic modulus is underestimated for tensile tests in the TD.

\subsection{Creep of alloyed foams}

The metallic foams placed in the exhaust line are mainly exposed to gas flow that creates forces on foam struts. The foams are loaded in compression 
and we expect them to deform especially at high temperature by creep deformation. The alloying of the pure $\mathrm{Ni}$ foams increases the creep resistance of the foams by solid solution strengthening mainly. The creep model given in [18] is used in this section. The alloyed foams were tested at temperatures in the $500-800{ }^{\circ} \mathrm{C}$ range for stresses in the 0.1-3MPa range. Moreover, the volume fraction range is relatively large (if we consider $\Phi_{m e c h}=\Phi_{N i}$ : $1.3-$ $3.2 \%$ or $\Phi_{\text {mech }}=\Phi_{\text {Alloyed }}: 2.8-8.4 \%$ ). Our large experimental data set enable an accurate validation of the creep model.

Two different approaches of foam creep modeling were developed in the literature. The approach in [18] accounts for a creep mechanism transition. The stress in the foam struts for a macroscopic stress $\sigma^{*}$ is estimated as follows:

$$
\sigma_{\text {strut }} \approx \frac{\sigma^{*}}{\Phi_{\text {mech }}}
$$

In this section, we do not make assumptions on the value of $\Phi_{m e c h}$. In table 4 , the range of the volume fraction and the range of applied stress in the struts during creep tests are computed for each alloyed foam.

\begin{tabular}{|c|c|c|c|c|}
\hline \multirow{2}{*}{$\begin{array}{c}\text { Alloyed } \\
\text { foam }\end{array}$} & \multirow{2}{*}{$\begin{array}{c}\Phi_{\text {mech }} \\
\text { label }\end{array}$} & \multicolumn{2}{|c|}{ Creep tests } & DPF application \\
\cline { 3 - 5 } & $\begin{array}{c}\sigma_{\text {strut }}(\mathrm{MPa}) \\
\sigma^{*}=2.5 \mathrm{MPa}\end{array}$ & $\begin{array}{c}\sigma_{\text {strut }}(\mathrm{MPa}) \\
\sigma^{*}=0.1 \mathrm{MPa}\end{array}$ & $\begin{array}{c}\sigma_{\text {strut }}(\mathrm{MPa}) \\
\sigma^{*}=0.01 \mathrm{MPa}\end{array}$ \\
\hline A763 8.4 & $3.2 \%-8.4 \%$ & $30-78$ & $1-3$ & $0.1-0.3$ \\
A782 6.8 & $2.5 \%-6.8 \%$ & $37-100$ & $1-4$ & $0.1-0.4$ \\
A790 4.9 & $2.1 \%-4.9 \%$ & $51-119$ & $2-5$ & $0.2-0.5$ \\
A793 4.7 & $1.9 \%-4.7 \%$ & $53-131$ & $2-5$ & $0.2-0.5$ \\
A808 7.6 & $2.6 \%-7.6 \%$ & $33-96$ & $1-4$ & $0.1-0.4$ \\
A809 5.5 & $2.1 \%-5.5 \%$ & $45-113$ & $2-5$ & $0.2-0.5$ \\
A810 3.8 & $1.6 \%-3.8 \%$ & $66-156$ & $3-6$ & $0.3-0.6$ \\
A811 2.8 & $1.3 \%-2.8 \%$ & $89-192$ & $4-8$ & $0.4-0.8$ \\
\hline
\end{tabular}

Table 4. Ranges of estimated applied stress in the struts during creep tests and in service conditions of alloyed foams.

In figure 7, the tested temperature-stress domain and the DPF application domain are localized to identify the creep deformation mechanism that occurs during the creep tests. At high stresses and high temperature, power-law creep occurs in the struts and at low stresses and low temperature, diffusional creep occurs in the struts. The creep tests were carried out in the transition between power-law creep domain and diffusional creep domain. This explains the slope transition in the log-log diagram 5 . The total foam creep rate is assumed to be the sum of two contributions. The power-law creep rate equation for bulk material is given by:

$$
\dot{\varepsilon}=K \sigma^{n} \exp \left(\frac{-Q}{R T}\right)
$$




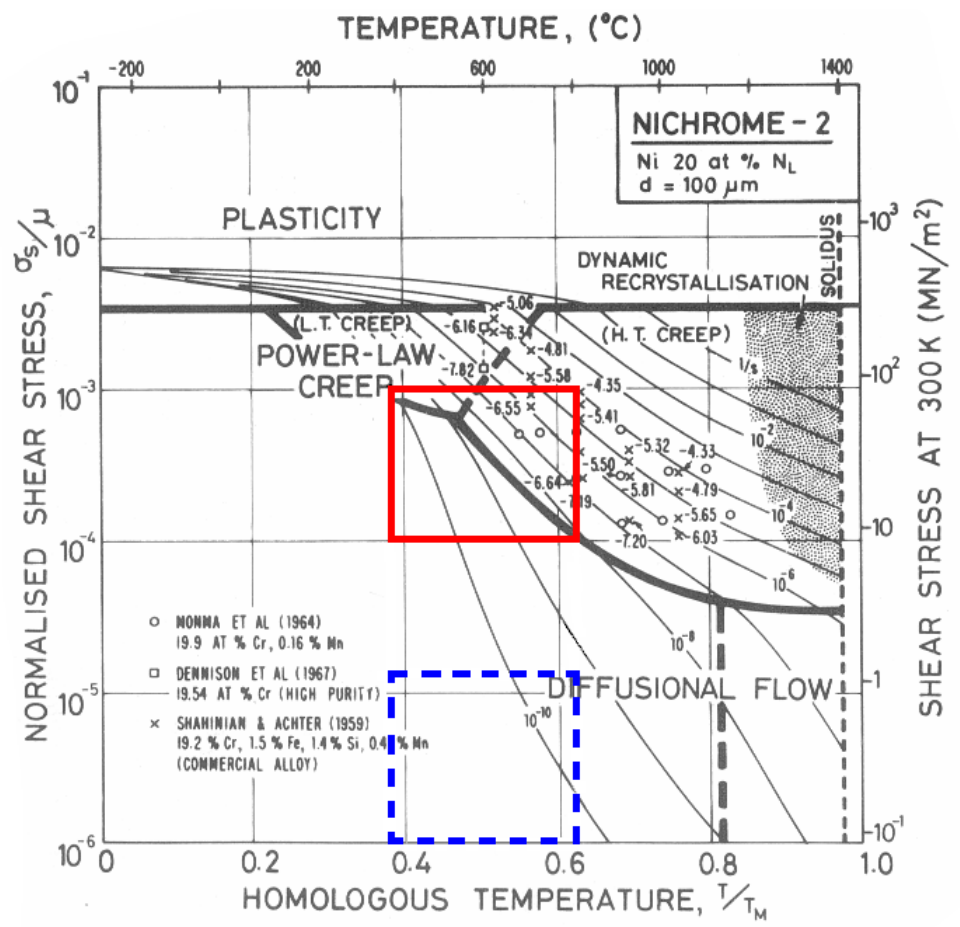

Fig. 7. Tested domain (black square) and DPF application domain (dashed square) in the deformation mechanism map of a typical $\mathrm{Ni}-20 \% \mathrm{Cr}$ alloy [11].

where $K$ is the Dorn constant, $n$ is the stress exponent, $Q$ is the activation energy, $R$ is the gas constant and $T$ is the temperature in Kelvin. The diffusional creep rate equation for bulk material is:

$$
\dot{\varepsilon}=\frac{14 \sigma \Omega}{\kappa T d^{2}} D_{e f f}, \quad \text { with } \quad D_{e f f}=D_{V}\left[1+\frac{\pi}{d} \frac{\delta D_{b}}{D_{V}}\right]
$$

where $\Omega$ is the atomic volume, $\kappa$ the Boltzmann constant, $d$ the grain size, and $D_{e f f}$ is the effective diffusion coefficient. $D_{V}$ is the diffusion coefficient for lattice diffusion of $\mathrm{Ni}$, and $\delta D_{b}$ the diffusion constant for boundary diffusion. The values of all the parameters are given in [11] for the typical Ni-20\% Cr alloy and are used for models computation of creep of the alloyed foams. Considering the "bamboo structure" of the Ni foams exhibited in [6], we take the grain size $d$ equal to $10 \mu \mathrm{m}$ that is to say the typical thickness of the walls of the struts.

In the first model, the deformation mechanism of the foam is assumed to be the bending of the struts [10]. We directly use the equations introduced in [18]. Thus, the total foam creep model equation can be written: 


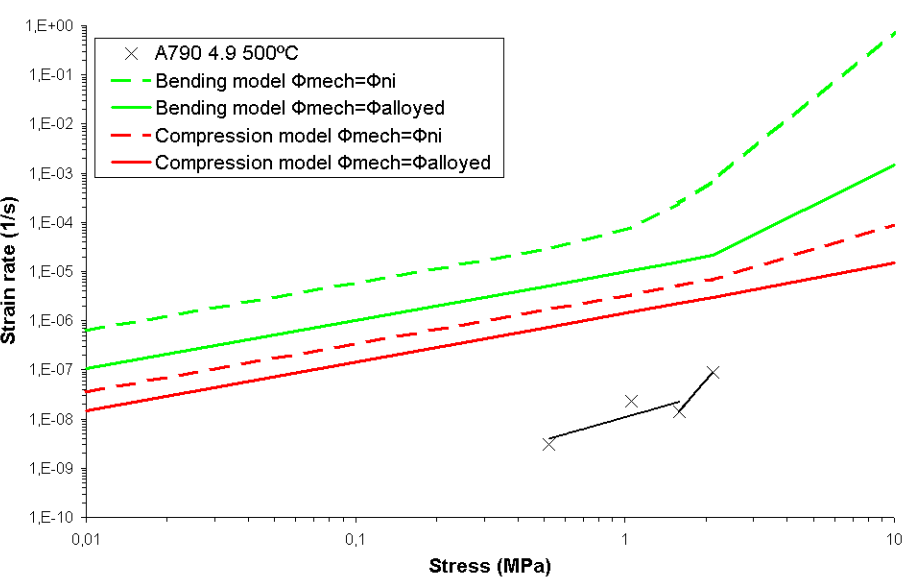

(a)

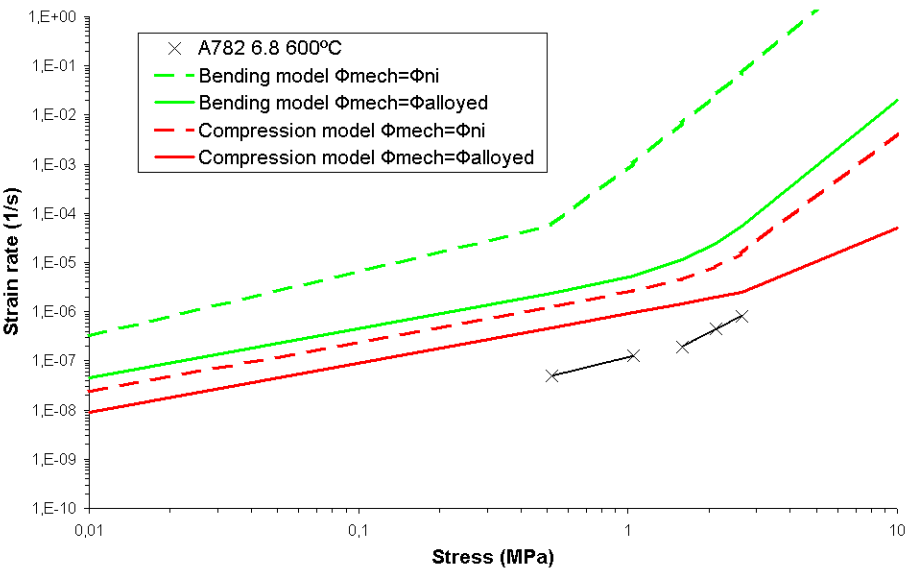

Fig. 8. Comparison between experimental creep data and both the bending model and the compression model based on power-law creep (high stresses) and diffusional creep (low stresses) of the struts of the (a) A790 4.9 at $500{ }^{\circ} \mathrm{C}$ (b) A782 6.8 at $600{ }^{\circ} \mathrm{C}$. The influence of mechanical volume fraction is plotted: solid lines represent the maximal volume fraction $\Phi_{\text {mech }}=\Phi_{\text {Alloyed }}$ (all the added mass on the foam during the sintering process contributes to mechanical properties) and dash lines represent the minimal volume fraction $\Phi_{m e c h}=\Phi_{N i}$ (the alloying of the foam only modifies the initial strut material).

$\dot{\varepsilon}^{b *}=K \frac{0.6}{(n+2)}\left(\frac{1.7(2 n+1)}{n}\right)^{n} \Phi_{\text {mech }}^{-(3 n+1) / 2} \sigma^{* n} \exp \left(\frac{-Q}{R T}\right)+\frac{14.3 \Omega}{\kappa T d^{2}} \sigma^{*} \Phi_{m e c h}^{-2} D_{e f f}$

The second model was developed in [16] and assumes that the foam deformation mechanism is the pure strut compression of beams oriented in the same direction as the loading direction. The total foam creep is in this model: 
(a)
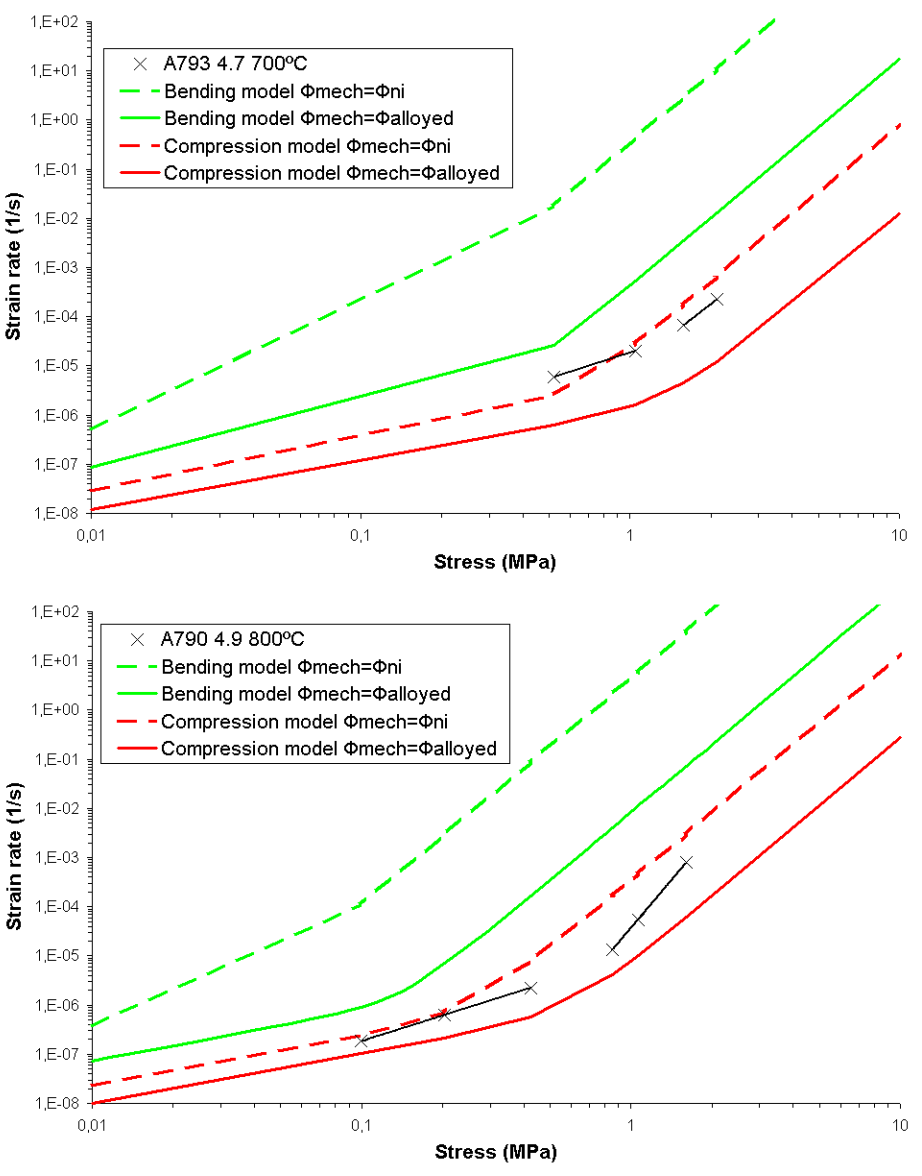

Fig. 9. Comparison between experimental creep data and both the bending model and the compression model based on power-law creep (high stresses) and diffusional creep (low stresses) of the struts of the (a) A793 4.7 at $700{ }^{\circ} \mathrm{C}$ (b) A790 4.9 at $800{ }^{\circ} \mathrm{C}$. The influence of mechanical volume fraction is plotted: solid lines represent the maximal volume fraction $\Phi_{\text {mech }}=\Phi_{\text {Alloyed }}$ (all the added mass on the foam during the sintering process contributes to mechanical properties) and dash lines represent the minimal volume fraction $\Phi_{m e c h}=\Phi_{N i}$ (the alloying of the foam only modifies the initial strut material).

$$
\dot{\varepsilon}^{c *}=K\left(\frac{\Phi_{m e c h}}{3}\right)^{-n} \sigma^{* n} \exp \left(\frac{-Q}{R T}\right)+\frac{14 \Omega}{\kappa T d^{2}} \sigma^{*}\left(\frac{\Phi_{m e c h}}{3}\right)^{-1} D_{e f f}
$$

Experimental creep data measured at $500{ }^{\circ} \mathrm{C}, 600^{\circ} \mathrm{C}, 700^{\circ} \mathrm{C}$, and $800^{\circ} \mathrm{C}$ are compared with both bending and compression model in figures 8 and 9 . The values that we used are proposed in [11]: $n=4.6, Q=285 \mathrm{~kJ} / \mathrm{mol}$, and $K=3.8 \mathrm{MPa}^{-4.6} \mathrm{~s}^{-1}$. The effect of "mechanical" volume fraction was also 
plotted, solid lines representing the real volume fraction model, the dash lines representing the initial $\mathrm{Ni}$ foam volume fraction. As observed in $[16,17,18]$, the compression model is in better agreement with the experimental data than the bending model that overpredicts by about two orders of magnitude the experimental data. We reach a good agreement at high temperature considering that $\Phi_{m e c h}=\Phi_{N i}$. This model overpredicts the experimental data at temperature below $600{ }^{\circ} \mathrm{C}$ by about two orders of magnitude. These results remain true for the other data that are not presented here.

\subsection{Finite element modelling of real foam microstructures}

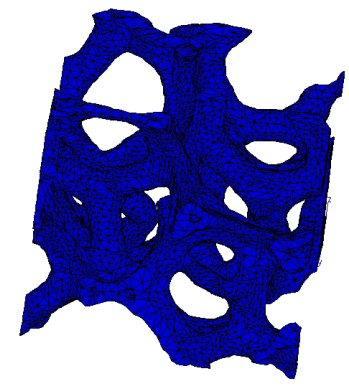

(a)

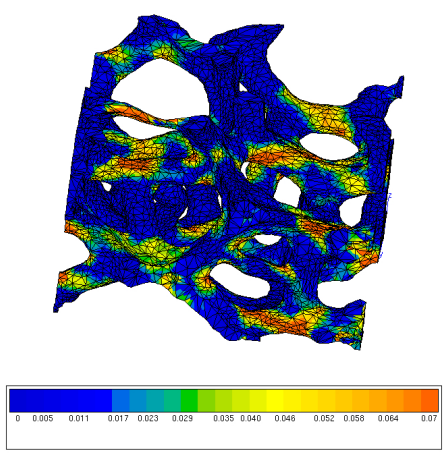

(c)
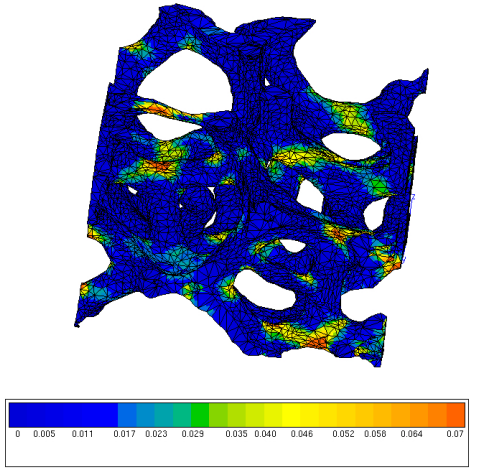

(b)

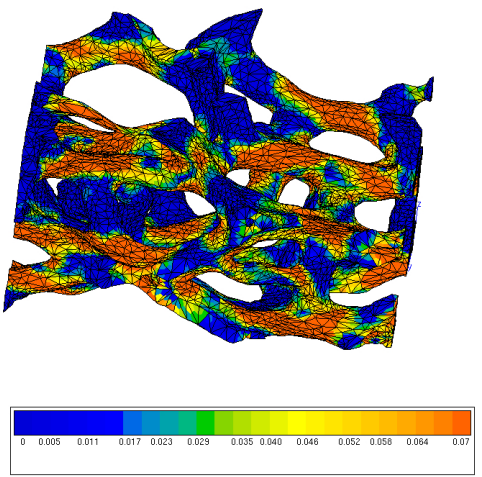

(d)

Fig. 10. Plastic deformation during a simulated tensile test of a foam cube with dimensions $800^{3} \mu \mathrm{m}^{3}$. Deformation is magnified by a factor 20 .

The increasing computing capacity enables us to perform more realistic simulations taking the actual shape of the cells into account. We used the finite element method on the microtomographic volume analyzed in [3] (a 


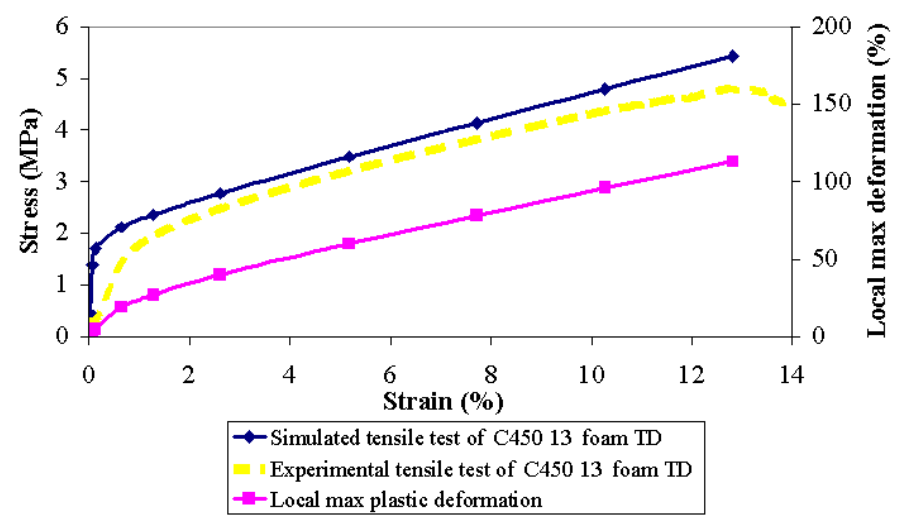

Fig. 11. Experimental and FEM simulated tensile tests of the C450 $13 \mathrm{Ni}$ foam at room temperature.

$200 \times 200 \times 99$ voxel) to identify the deformation mechanisms of the foam during monotonic tensile tests.

The Amira ${ }^{\mathrm{TM}}$ software is used to generate a mesh from the raw binary figures cropped to a $800 \times 800 \times 800 \mu \mathrm{m}^{3}$ volume. The considered volume contains about 4 cells. The foam surface is first triangulated with the help of the marching cube algorithm and the number of triangles is set to a reasonable number. Then, a volume mesher generates a tetrahedral mesh using the advancing front method. The obtained mesh has 77000 elements. The measured volume fraction was $19 \%$ whereas the real volumic fraction is only $13 \%$. This procedure provides meshes with a very good quality that can be directly implemented in the ZeBuLon ${ }^{\mathrm{TM}}$ finite element code. We used second order tetrahedral elements [19]. The behavior law of $\mathrm{Ni}$ is the elastic-plastic law with linear hardening identified in section 4.1. Node sets are created on the opposite faces of the cube volume element in direction TD. One of the node set displacement is prescribed to 0 and the other is set to 10 pixel in the TD.

The computation was performed with a single PC (2 GHz CPU frequency and $4 \mathrm{~Gb}$ memory) within 13 hours. In figure 10, the plastic deformation map is presented. Plastic deformation initiate mainly at the nodes. The local plastic deformation is much higher than the overall foam deformation. At higher deformation levels, the plastic deformation is located in the struts the direction of which is parallel to the loading direction. These struts are loaded in tension. The other struts undergo very low deformation. We post-processed the computation to get a macroscopic stress-strain. In figure 11, we plot the maximum local plastic deformation and the average stress in direction RD vs. the macroscopic strain. The simulated elastic modulus is too high in comparison to the experiment, but the plastic slopes are in very good agreement. We report a factor 10 between the local maximum plastic deformation and the 
global foam deformation. This means that there is practically no pure elastic regime in a foam tensile test.

One possible reason for the discrepancy between the computed and experimental elastic stiffness may be the size of the volume element considered which is probably far from the representative volume element size of the material, at least for elastic properties. The elastic bending of some particular struts is found to be the first mechanism that occurs in the foam, assumed in the simple model of section 4.1 .

\section{References}

1. V. Paserin, S. Marcuson, J. Shu, D.S. Wilkinson: CVD Technique for Inco Nickel Foam Production, Advanced Engineering Materials 6 No. 6, 2004.

2. J. Banhart: Manufacture, characterisation and application of cellular metals and metal foams, Progress in Materials Science 46 (2001) 559-632.

3. T. Dillard, F. N'Guyen, E. Maire, L. Salvo, S. Forest, Y. Bienvenu, J.D Bartout, M. Croset, R. Dendievel, P. Cloetens: 3D quantitative image analysis of open-cell nickel foams under tension and compression loading using X-ray microtomography, Philosophical Magazine Vol. 85 No. 19, July 2005, 2147-2175.

4. A. Benouali, L. Froyen, T. Dillard, S. Forest, F. NGuyen: Investigation on the influence of cell shape anisotropy on the mechanical performance of closed cell aluminium foams using micro-computed tomography, Journal of Materials Science Vol. 40, 2005, 5801-5811.

5. P.S Liu: Tensile fracture behavior of foamed metallic materials, Material Science and Engineering A 384 (2004) 352-354.

6. V. Goussery, Y. Bienvenu, S. Forest, A.F. Gourgues, C. Colin, J.D. Bartout: Grain Size Effects on the Mechanical Behavior of Open-cell Nickel Foams, Advanced Engineering Materials 6 No. 6, 2004.

7. X. Badiche, S. Forest, T. Guibert, Y. Bienvenu, J.D. Bartout, P. Ienny, M. Croset, H. Bernet: Mechanical properties and non-homogeneous deformation of open-cell nickel foams: application of the mechanics of cellular solids and of porous materials, Materials Science and Engineering A 289 (2000) 276-288.

8. E. Maire, L. Babout, J.-Y. Buffière, R. Fougères: Recent results on 3D characterization of microstructure and damage of metal matrix composites and a metallic foam using X-ray tomography, Materials Science and Engineering A 319-321 (2001) 216-219.

9. E. Maire, A. Fazekas, L. Salvo, R. Dendievel, S. Youssef, P. Cloetens, J.M. Letang: X-ray tomography applied to the characterization of cellular materials. Related finite element modeling problems, Composites Science and Technology 63 (2003) 2431-2443.

10. L.J. Gibson, M.F. Ashby: Cellular solids. Structure and properties - Second edition, Cambridge University Press, Cambridge, 1997.

11. H.J. Frost, M.F Ashby: Deformation-Mechanism Maps: the Plasticity and Creep of Metals and Ceramics, Pergamon Press, New York, NY, 1982.

12. D.T. Queheillalt, D.D. Hass, D.J. Sypeck, H.N.G Wadley: Synthesis of open-cell metal foams by templated directed vapor deposition, J. Mater. Res., 16 No. 4, 2001. 
13. P. Quadbeck, J. Kaschta, R.F. Singer: Superalloy IN625 with Cellular Microstructure - Fabrication Route and Mechanical Properties, Advanced Engineering Materials 6 No. 8, 2004.

14. D.T. Queheillalt, Y. Katsumura, H.N.G Wadley: Synthesis of stochastic open cell Ni-based foams, Scripta Materialia, 50, 313 - 317, 2004.

15. E.W. Andrews, L.J. Gibson, M.F. Ashby: The creep of cellular solids, Acta Mater. Vol. 47, No. 10 (1999).

16. A. Hodge, D. Dunand: Measurement and Modelling of Creep in Open-Cell NiAl Foams, Metallurgical and Materials Transactions 34A (2003) 2353-2362.

17. H. Choe, D. Dunand: Synthesis, structure, and mechanical properties of $\mathrm{Ni}-\mathrm{Al}$ and Ni-Cr-Al superalloy foams, Acta Materialia 52(2004) 1283-1295.

18. H. Choe, D. Dunand: Mechanical properties of oxidation-resistant $\mathrm{Ni}$-Cr foams, Materials Science and Engineering A 384 (2004) 184-193.

19. S. Youssef, E. Maire, R. Gaertner: Finite element modelling of the actual structure of cellular materials determined by X-ray tomography, Acta Materialia 53 (2005) 719-730. 